\title{
Ritmos biológicos: como o mau uso de smartphones pode influenciar negativamente o sono
}

\author{
Biological rhythms: how the misuse of smartphones can \\ negatively influence sleep
}

\begin{abstract}
Ritmos biológicos: cómo el mal uso de los teléfonos inteligentes puede influir negativamente en el sueño
\end{abstract}

\author{
Arthur da Silva Santos ${ }^{1}$, Edineuza Aparecida de Freitas ${ }^{2}$
}

\begin{abstract}
1.Faculdade do Futuro, Sem Departamento, Manhuaçu-MG, Brasil. ORCID https://orcid.org/0000-0002-4312-2388

2.Faculdade do Futuro, Sem Departamento, Manhuaçu-MG, Brasil. ORCID https://orcid.org/0000-0001-8107-1457
\end{abstract}

\begin{abstract}
Resumo
Objetivos. Buscar conhecimentos aprofundados acerca da fisiologia do sono e seus mecanismos; entender a relação entre a exposição à luz dos dispositivos eletrônicos e os mecanismos do sono; buscar formas para amenizar os efeitos negativos, a fim de se ter uma qualidade de vida melhor. Método. Revisão integrativa da literatura utilizando as bases de dados PubMed, para busca de materiais em inglês, e a base Google Acadêmico, para busca de materiais em português. Resultados. A pesquisa inicial encontrou 4067 resultados, que após todo o processo de seleção foram 33 artigos analisados. Conclusão. O Ciclo Circadiano é de suma importância para o corpo e a manutenção da homeostasia, ressalta-se que a população precisa ser alertada para um uso moderado dos dispositivos emissores de luz e educada para a utilização de artifícios que reduzam a emissão de luz nociva que desregula este ciclo, a fim de se ter uma melhora na qualidade de vida.
\end{abstract}

Unitermos. Sono; Dispositivos eletrônicos; Ciclo circadiano; Desregulação

\begin{abstract}
Objective. To search knowledge about sleep physiology and its mechanisms; understand the relationship between light exposure from electronic devices and sleep mechanisms; search ways to mitigate the negative effects to have a better quality of life. Method. Integrative literature review using the PubMed databases, to search for materials in English, and the Academic Google database, to search for materials in Portuguese. Results. The initial search found 4067 results, which after the entire selection process, 33 articles were analyzed. Conclusion. The Circadian Cycle is of paramount importance for the body and the maintenance of homeostasis, it is noteworthy that the population needs to be alerted to a moderate use of light emitting devices and educated in the use of devices that reduce harmful light emission that deregulates this cycle, to have an improvement in the quality of life.
\end{abstract}

Keywords. Sleep; Electronic devices; Circadian cycle; Deregulation

\section{Resumen}

Objetivo. Buscar un conocimiento profundo sobre la fisiología del sueño y sus mecanismos; comprender la relación entre la exposición a la luz de los dispositivos electrónicos y los mecanismos del sueño; buscar formas de mitigar los efectos negativos para tener una mejor calidad de vida. Método. Revisión integrativa de la literatura utilizando las bases de datos PubMed para buscar materiales en inglés y la base de datos Academic Google para buscar 
materiales en portugués Resultados. La búsqueda inicial encontró 4067 resultados, que luego de todo el proceso de selección, se analizaron 33 artículos. Conclusión. El Ciclo Circadiano es de suma importancia para el organismo y el mantenimiento de la homeostasis, cabe destacar que la población necesita estar alerta a un uso moderado de dispositivos emisores de luz y educada en el uso de dispositivos que reduzcan la emisión de luz nociva que desregula este ciclo, para tener una mejora en la calidad de vida.

Palabras clave. Dormir; Dispositivos electrónicos; Ciclo circadiano; Desregulación

Trabalho realizado na Faculdade do Futuro, Manhuaçu-MG, Brasil.

\section{INTRODUÇÃO}

O ser humano sempre buscou uma forma de coletar e processar dados. Com a descoberta e desenvolvimento dos transistores, foi possível a fabricação de computadores que elevaram esse poder de processamento exponencialmente. Em razão deste crescimento tecnológico, foi possível encolher os computadores até o ponto em que passaram a caber nos bolsos, estes dispositivos ficaram conhecidos como smartphones e estão atualmente presentes em quase toda a sociedade ${ }^{1}$.

A fim de que as informações processadas pudessem ser utilizadas de maneira útil no cotidiano, os smartphones e outros aparelhos contam com a presença de telas, que transformam os cálculos realizados em imagens que os usuários podem interagir. Destaca-se, portanto, que os dispositivos eletrônicos emitem luz, sendo ela nada mais que a parte do espectro eletromagnético que o cérebro consegue captar e interpretar, seu comprimento de onda está compreendido entre 380 e 740nm e varia de azul (com 
ondas mais curtas e frequências altas) a vermelho (com ondas mais longas e frequências mais baixas) ${ }^{2}$.

Entretanto, a utilização dessas telas pode trazer malefícios, como a desregulação do ciclo do sono, sendo este mecanismo essencial para manutenção homeostática do corpo. Essa desregulação pode interferir na homeostase e se dá a partir do momento em que se utiliza os smartphones à noite, período em que o corpo deveria estar em um ambiente totalmente escuro, o momento o ideal para o sono ${ }^{3}$.

Portanto, entende-se que o corpo humano encontra-se em atividade nos períodos diurnos e em repouso nos períodos noturnos. A essa alternância damos o nome de Ciclo Circadiano, que dura aproximadamente 24h, e pode mudar de pessoa para pessoa, devido a aspectos biológicos e hábitos sociais. Ele é controlado por diversos fatores, sendo a presença/ausência de luz possivelmente o mais importante destes ${ }^{4}$.

Conforme o apresentado nota-se que atualmente não é de conhecimento geral os efeitos negativos que os dispositivos eletrônicos podem trazer. Sendo assim, esta pesquisa visa: buscar conhecimentos aprofundados acerca da fisiologia do sono e seus mecanismos; entender a relação entre a exposição à luz dos dispositivos eletrônicos e os mecanismos do sono; buscar formas para amenizar os efeitos negativos, a fim de se ter uma qualidade de vida melhor. Entende-se que a população nem sempre sabe que dispositivos eletrônicos podem trazer malefícios, por isso 
torna-se relevante levar essa informação às pessoas a fim de alertá-las sobre potenciais riscos à saúde.

\section{MÉTODO}

A fim de cumprir os objetivos deste estudo, a pesquisa foi realizada através do método de revisão integrativa da literatura. A pesquisa iniciou-se após a determinação dos descritores, sendo estes as expressões: "luz artificial à noite", "interrupção circadiana", "exposição à luz azul" e "influência dos smartphones no sono", além de seus equivalentes em inglês. Definidos os descritores, partiu-se então para a escolha das bases de dados.

Testando-se diferentes bases de dados, verificou-se que algumas não tinham quantidades satisfatórias de conteúdo a ser utilizado. Ao fim, foram selecionados dois bancos de dados online: Google Acadêmico para conteúdo em português e PubMed para artigos na língua inglesa.

Como critérios de inclusão optou-se por artigos que atendessem os seguintes parâmetros: conteúdos publicados no período dos últimos 10 anos, de acesso gratuito e nas línguas inglesa ou portuguesa. Já os critérios de exclusão escolhidos foram: artigos que tratassem de espécies diferentes da humana, que somente citassem 0 sono sem abordar os seus aspectos fisiológicos e/ou fatores que podem interferir no ciclo do sono, e que, embora tratassem do tema, não abordassem especificamente os aspectos fisiológicos do mesmo. 


\section{RESULTADOS}

A pesquisa inicial retornou 4067 resultados, somandose ambas as plataformas. Após a aplicação dos critérios de inclusão e exclusão e através dos filtros disponíveis em cada plataforma, este número foi reduzido a 2816 resultados. Após a seleção por títulos condizentes com 0 tema, o número diminuiu para 94 artigos. Partiu-se então para a leitura de resumos, o número total de conteúdos que passaram nessa etapa foi 61 .

No fim, depois de uma leitura detalhada e confecção da tabela de resultados, o total utilizado para análise final e confecção do estudo foi 33, sendo estes os que mais se encaixaram na proposta abordada.

Nota-se uma queda drástica na quantidade de artigos analisados, uma vez que a pesquisa inicial se mostra muito abrangente e superficial. Sendo assim, à medida que os artigos são analisados através das etapas supracitadas, é possível ver um afunilamento e consequente diminuição daqueles não condizentes à pesquisa.

Um fluxograma resumindo as etapas acima descritas foi confeccionado e encontra-se na Tabela 1.

A Tabela 2 apresenta um resumo dos artigos analisados. 


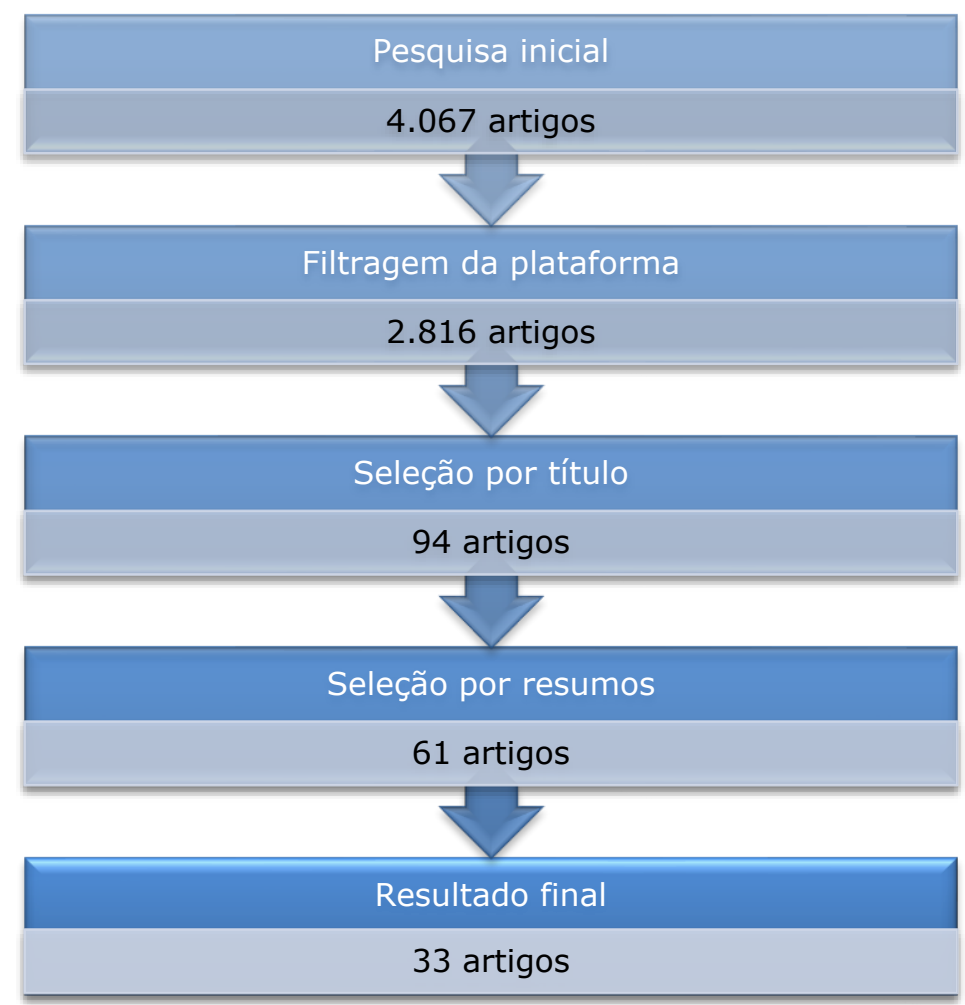

\section{DISCUSSÃO}

\section{A luz e o ser humano}

O ser humano se comunica com o mundo exterior de várias formas. Nossos sentidos são a tradução que o nosso cérebro dá às informações captadas pelo meio externo através de estruturas especializadas na captação de diferentes tipos de estímulos, e a luz certamente é uma das informações mais importantes, pois permite 0 funcionamento da nossa visão, e os olhos contam com uma complexa maquinaria utilizada na interpretação da mesma ${ }^{36}$. 
Tabela 2. Apresentação dos resultados obtidos após estudo dos materiais.

\begin{tabular}{|c|c|c|c|}
\hline Título & Autor (es) & Ano & Resultados \\
\hline $\begin{array}{l}\text { A frequência da utilização de } \\
\text { videojogos e sua influência na } \\
\text { qualidade do sono de crianças } \\
\text { em idade escolar }\end{array}$ & $\begin{array}{l}\text { Maria Juliana Porte } \\
\text { Cercatti }\end{array}$ & $2018^{5}$ & $\begin{array}{l}\text { O estudo conclui que há uma relação negativa } \\
\text { entre utilização de jogos eletrônicos antes de } \\
\text { dormir e a qualidade sono. Além disso, os } \\
\text { autores inferem que há uma relação destes } \\
\text { fatores à dificuldade de dormir e à sonolência } \\
\text { diurna. }\end{array}$ \\
\hline $\begin{array}{l}\text { A luz irrompe onde já nenhum } \\
\text { sol brilha }\end{array}$ & Raul Cerveira Lima & $2018^{6}$ & $\begin{array}{l}\text { O autor destaca fontes de poluição luminosa e } \\
\text { impactos que a mesma pode causar, } \\
\text { destacando inclusive os impactos no sono. }\end{array}$ \\
\hline $\begin{array}{l}\text { Análise comparativa dos } \\
\text { padrões de sono entre } \\
\text { adolescentes do ensino médio } \\
\text { e superior }\end{array}$ & $\begin{array}{l}\text { Fernanda Mayara } \\
\text { Crispim Diogo }\end{array}$ & $2018^{7}$ & $\begin{array}{l}\text { O estudo comparou os hábitos de adolescentes } \\
\text { de fases distintas da vida estudantil e concluiu } \\
\text { que tanto estudantes do ensino médio, quanto } \\
\text { do ensino superior mantém hábitos inadequados } \\
\text { de sono, e que estes hábitos influenciam o } \\
\text { desempenho acadêmico dos mesmos. }\end{array}$ \\
\hline $\begin{array}{l}\text { Artificial light at night: } \\
\text { melatonin as a mediator } \\
\text { between the environment and } \\
\text { epigenome }\end{array}$ & $\begin{array}{l}\text { Abraham Haim, Abed E. } \\
\text { Zubidat }\end{array}$ & $2015^{8}$ & $\begin{array}{l}\text { O estudo estabelece uma relação entre a luz } \\
\text { artificial à noite e a incidência de câncer, além } \\
\text { de tentar compreender a interação da } \\
\text { melatonina com células cancerígenas. }\end{array}$ \\
\hline $\begin{array}{l}\text { Artificial light-at-night - a } \\
\text { novel lifestyle risk factor for } \\
\text { metabolic disorder and cancer } \\
\text { morbidity }\end{array}$ & $\begin{array}{l}\text { Abed E. Zubidat, } \\
\text { Abraham Haim }\end{array}$ & $2017^{9}$ & $\begin{array}{l}\text { Os autores relacionam a interrupção circadiana } \\
\text { por luz à noite com desordens metabólicas, } \\
\text { obesidade e câncer. O estudo ainda sugere a } \\
\text { melatonina como potencial alvo para } \\
\text { desenvolvimento de drogas para tratamento de } \\
\text { doenças relacionadas a distúrbios circadianos. }\end{array}$ \\
\hline $\begin{array}{l}\text { Aspectos cronobiológicos da } \\
\text { síndrome do comer noturno }\end{array}$ & $\begin{array}{l}\text { Ana Beatriz Cauduro } \\
\text { Harb }\end{array}$ & $2013^{10}$ & $\begin{array}{l}\text { O estudo sugere uma ligação entre os relógios } \\
\text { biológicos e os horários de alimentação. Além } \\
\text { disso, os autores enfatizam que indivíduos com } \\
\text { desregulações no ciclo circadiano podem } \\
\text { desenvolver a síndrome do comer noturno, que } \\
\text { ocasiona um maior consumo de alimentos em } \\
\text { períodos em que o corpo deveria estar } \\
\text { descansando. }\end{array}$ \\
\hline $\begin{array}{l}\text { Association between light at } \\
\text { night, melatonin secretion, } \\
\text { sleep deprivation, and the } \\
\text { internal clock: health impacts } \\
\text { and mechanisms of circadian } \\
\text { disruption }\end{array}$ & $\begin{array}{l}\text { Yvan Touitou, } \\
\text { Alain Reinberg, } \\
\text { David Touitou }\end{array}$ & $2017^{11}$ & $\begin{array}{l}\text { Os autores abordam aspectos da fisiologia do } \\
\text { ciclo circadiano e sugerem relações entre sua } \\
\text { desregulação com problemas de saúde, tais } \\
\text { como câncer, obesidade, problemas vasculares } \\
\text { e diabetes. }\end{array}$ \\
\hline $\begin{array}{l}\text { Avaliação da qualidade do sono } \\
\text { na perspectiva do conforto } \\
\text { para o pós-graduando em } \\
\text { enfermagem }\end{array}$ & $\begin{array}{l}\text { Andrea Dos Santos } \\
\text { Garcia }\end{array}$ & $2018^{12}$ & $\begin{array}{l}\text { A autora observou, empiricamente, estudantes } \\
\text { de pós-graduação e notou que estes } \\
\text { reclamavam de problemas de sono. A partir } \\
\text { disso, ela realizou o estudo para avaliar } \\
\text { qualidade e quantidade do sono a fim de } \\
\text { determinar os fatores que influenciam o sono, } \\
\text { concluindo-se que hábitos e rotinas podem } \\
\text { influenciar negativamente este ciclo. }\end{array}$ \\
\hline $\begin{array}{l}\text { Avaliação do efeito do "jogo } \\
\text { quarto perfeito: aprenda a } \\
\text { dormir bem" nos parâmetros e } \\
\text { hábitos de sono de crianças } \\
\text { saudáveis }\end{array}$ & $\begin{array}{l}\text { Maria Emanuela Matos } \\
\text { Leonardo }\end{array}$ & $2018^{13}$ & $\begin{array}{l}\text { Os autores, ao observarem uma qualidade de } \\
\text { sono ruim em crianças, desenvolveram um jogo } \\
\text { de tabuleiro educativo para ensiná-las a } \\
\text { importância do sono. A partir disso, observaram } \\
\text { se houve melhoria do sono após a implantação } \\
\text { do jogo. }\end{array}$ \\
\hline $\begin{array}{l}\text { Can sleep quality and wellbeing } \\
\text { be improved by changing the } \\
\text { indoor lighting in the homes of } \\
\text { healthy, elderly citizens? }\end{array}$ & $\begin{array}{l}\text { Birgit Sander, Jakob } \\
\text { Markvart, Line Kessel, } \\
\text { Aikaterini Argyraki, } \\
\text { Kjeld Johnsen }\end{array}$ & $2015^{14}$ & $\begin{array}{l}\text { O estudo abordou a relação da luz com o ritmo } \\
\text { circadiano. Os indivíduos estudados foram } \\
\text { pessoas saudáveis e com idades a maiores que } \\
65 \text { anos. Estes receberam diferentes } \\
\text { tratamentos de luz durante determinado período } \\
\text { a fim de se determinar se há ou não melhorias } \\
\text { na qualidade de sono caso a luz recebida pelos } \\
\text { olhos tenha diferentes frequências. }\end{array}$ \\
\hline
\end{tabular}


Tabela 2 (cont.). Apresentação dos resultados obtidos após estudo dos materiais.

\begin{tabular}{|c|c|c|c|}
\hline $\begin{array}{l}\text { Ciclos de atividade/repouso e } \\
\text { alimentação/jejum associados } \\
\text { ao uso de } \\
\text { Equipamentos eletrônicos: } \\
\text { aspectos comportamentais e } \\
\text { padrões temporais }\end{array}$ & Tatiana Harumi Seito & $2017^{3}$ & $\begin{array}{l}\text { O estilo de vida contemporâneo, com a } \\
\text { iluminação elétrica, flexibilização de horários e } \\
\text { utilização de equipamentos eletrônicos, } \\
\text { aumenta o desafio da sincronização dos ritmos } \\
\text { do corpo. } \\
\text { Atrasos decorrentes desse estilo de vida podem } \\
\text { levar a conflitos temporais, prolongando os } \\
\text { horários de vigília, diminuindo os horários de } \\
\text { sono e provocando uma ingesta alimentar em } \\
\text { horários não propícios. }\end{array}$ \\
\hline $\begin{array}{l}\text { Correlação entre a exposição } \\
\text { diária à luz azul violeta emitida } \\
\text { por dispositivos digitais e a } \\
\text { visão de adultos jovens }\end{array}$ & $\begin{array}{l}\text { Ludmila Caroline Silva, } \\
\text { Letícia Danielly Maia, } \\
\text { Deborah Renata } \\
\text { Pinheiro, Laís Da Silva } \\
\text { Machado Matias, } \\
\text { Vinícius Fernandes } \\
\text { Salvo, Jacqueline De } \\
\text { Oliveira André, Giselle } \\
\text { Foureaux }\end{array}$ & $2015^{15}$ & $\begin{array}{l}\text { Os autores demonstraram a relação da luz com } \\
\text { a visão e a sensibilidade dos olhos } \\
\text { especialmente à faixa azul da luz. Demonstrou- } \\
\text { se que os receptores na retina são sensíveis à } \\
\text { luminosidade e facilmente danificados pela } \\
\text { mesma. Além disso, relacionaram a emissão de } \\
\text { luz de dispositivos eletrônicos com danos visuais } \\
\text { causados por luminosidade. }\end{array}$ \\
\hline $\begin{array}{l}\text { Daily and seasonal variation in } \\
\text { the spectral composition of } \\
\text { light exposure in humans }\end{array}$ & $\begin{array}{l}\text { Helen C. Thorne, Kay H. } \\
\text { Jones, Stuart P. Peters, } \\
\text { Simon N. Archer, Derk- } \\
\text { Jan Dijk }\end{array}$ & $2009^{16}$ & $\begin{array}{l}\text { Constatou-se que há diferenças na exposição a } \\
\text { cada faixa de luz ao longo do dia e das } \\
\text { estações. A exposição à luz azul, dependendo } \\
\text { do horário do dia, pode ser benéfica. Sendo } \\
\text { assim, o corpo reage de forma diferente a estas } \\
\text { diferenças e utiliza dessas mudanças para } \\
\text { sincronizar seus ritmos biológicos. }\end{array}$ \\
\hline $\begin{array}{l}\text { Differences in twenty-four-hour } \\
\text { profiles of blue-light exposure } \\
\text { between day and night shifts in } \\
\text { female medical staff }\end{array}$ & $\begin{array}{l}\text { Sylvia Rabstein, } \\
\text { Katarzyna Burek, Martin } \\
\text { Lehnert, Alexandra } \\
\text { Beine, Céline } \\
\text { Vetter; Volker Harth, } \\
\text { Simone Putzke, Thomas } \\
\text { Kantermann, Jörg } \\
\text { Walther, Rui Wang- } \\
\text { Sattler, Dirk Pallapies, } \\
\text { Thomas Brüning, } \\
\text { Thomas Behrens }\end{array}$ & $2019^{17}$ & $\begin{array}{l}\text { O estudo apontou a luz como um dos } \\
\text { sincronizadores dos relógios internos do corpo e } \\
\text { a luz à noite como um problema à saúde. } \\
\text { Realizaram medições para determinar se fatores } \\
\text { individuais como cronótipo, idade e hábitos } \\
\text { influenciam na exposição que cada indivíduo } \\
\text { tem à incidência de luz ao longo do dia. Ao fim } \\
\text { concluíram que trabalhadores por turnos têm } \\
\text { menos horas por dia de escuridão à noite, que a } \\
\text { incidência de luz azul é maior durante o dia e } \\
\text { que fatores individuais influenciam na exposição } \\
\text { à luz. }\end{array}$ \\
\hline $\begin{array}{l}\text { Do green-blocking glasses } \\
\text { enhance the nonvisual effects } \\
\text { of white polychromatic light? }\end{array}$ & $\begin{array}{l}\text { Soomin Lee, Naoshi } \\
\text { Kakitsuba, Tetso } \\
\text { Katsuura }\end{array}$ & $2018^{18}$ & $\begin{array}{l}\text { O artigo aponta a influência negativa da luz azul } \\
\text { ao corpo e como lentes oculares bloqueadoras } \\
\text { são capazes de contornar alguns destes } \\
\text { malefícios. O artigo demonstrou o experimento } \\
\text { com lentes bloqueadoras de faixas verdes, azuis } \\
\text { e lentes controle, sem bloqueio de luz. O estudo } \\
\text { conclui que contração pupilar e efeitos não } \\
\text { visuais são diferentes de acordo com a lente } \\
\text { bloqueadora usada. }\end{array}$ \\
\hline $\begin{array}{l}\text { Effects of a chronic reduction } \\
\text { of short-wavelength light input } \\
\text { on melatonin and sleep } \\
\text { patterns in humans: Evidence } \\
\text { for adaptation }\end{array}$ & $\begin{array}{l}\text { Marina C. Giménez, } \\
\text { Domien G. M. Beersma, } \\
\text { Pauline Bollen, Matthijs } \\
\text { L. Van Der Linden, } \\
\text { Marijke C. M. Gordijn }\end{array}$ & $2014^{19}$ & $\begin{array}{l}\text { O estudo investigou se a redução da absorção } \\
\text { ocular de luzes de ondas curtas gera efeitos nos } \\
\text { ritmos do sono e na supressão noturna de } \\
\text { melatonina. Os indivíduos estudados utilizaram } \\
\text { lentes de contato que reduziam a incidências de } \\
\text { luz azul que atingia os olhos. Concluiu-se que a } \\
\text { supressão de melatonina foi menor após o uso } \\
\text { das lentes, mas dado o tempo do estudo, não } \\
\text { foram encontradas mudanças significativas nos } \\
\text { ritmos biológicos. }\end{array}$ \\
\hline $\begin{array}{l}\text { Effects of blue light on the } \\
\text { circadian system and eye } \\
\text { physiology }\end{array}$ & $\begin{array}{l}\text { Gianluca Tosini, Ian } \\
\text { Ferguson, Kazuo } \\
\text { Tsubota }\end{array}$ & $2016^{20}$ & $\begin{array}{l}\text { Os pesquisadores realizaram uma revisão da } \\
\text { bibliografia para determinar o conhecimento que } \\
\text { se tinha, até o momento em que realizaram o } \\
\text { estudo, sobre a influência da faixa de luz azul } \\
\text { sobre a regulação da fisiologia ocular e a saúde } \\
\text { dos olhos. }\end{array}$ \\
\hline
\end{tabular}


Tabela 2 (cont.). Apresentação dos resultados obtidos após estudo dos materiais.

\begin{tabular}{|c|c|c|c|}
\hline $\begin{array}{l}\text { Filtro Amarelo e o Ritmo } \\
\text { Circadiário }\end{array}$ & $\begin{array}{l}\text { João Paulo Cunha, } \\
\text { Joana Ferreira, Teresa } \\
\text { Paiva, António } \\
\text { Castanheira-Dinis }\end{array}$ & $2011^{21}$ & $\begin{array}{l}\text { Os autores compararam idosos submetidos à } \\
\text { cirurgia de correção de catarata e estudaram os } \\
\text { efeitos no sistema circadiano, chegando à } \\
\text { conclusão que idosos com catarata tem má } \\
\text { qualidade de sono e sonolência diurna e que a } \\
\text { cirurgia corretiva melhora o ciclo sono-vigília, } \\
\text { uma vez que melhora a exposição da retina à } \\
\text { luz. }\end{array}$ \\
\hline Melatonina e glândula pineal & $\begin{array}{l}\text { Fernanda G. Kasecker, } \\
\text { Carlos P. Nunes }\end{array}$ & $2017^{22}$ & $\begin{array}{l}\text { Os autores abordaram aspectos fisiológicos, } \\
\text { como a importância da melatonina na regulação } \\
\text { das funções do corpo e a sua importância na } \\
\text { regulação do sono. Ao fim do estudo, os autores } \\
\text { chegaram à conclusão que a suplementação da } \\
\text { melatonina é capaz de melhorar o sono } \\
\text { diretamente em três aspectos: propensão a } \\
\text { dormir, tempo necessário para adormecer e } \\
\text { sonolência. }\end{array}$ \\
\hline $\begin{array}{l}\text { Nocturnal light pollution and } \\
\text { underexposure to daytime } \\
\text { sunlight: Complementary } \\
\text { mechanisms of circadian } \\
\text { disruption and related diseases }\end{array}$ & $\begin{array}{l}\text { Michael H. Smolensky, } \\
\text { Linda L. Sackett- } \\
\text { Lundeen, Francesco } \\
\text { Portaluppi }\end{array}$ & $2015^{23}$ & $\begin{array}{l}\text { Pensando nisso, o artigo explorou, através de } \\
\text { uma revisão de literatura, os efeitos causados } \\
\text { por pouca exposição ao sol durante o dia, } \\
\text { causando deficiência de vitamina D, e muita } \\
\text { exposição à luz artificial à noite, causando } \\
\text { deficiência de melatonina. }\end{array}$ \\
\hline $\begin{array}{l}\text { O impacto da restrição crónica } \\
\text { de sono na função cognitiva e } \\
\text { humor em adolescentes }\end{array}$ & $\begin{array}{l}\text { Fernanda Ariana Santos } \\
\text { Silveira }\end{array}$ & $2017^{24}$ & $\begin{array}{l}\text { O estudo demonstra que, com a criação da } \\
\text { iluminação elétrica, os hábitos de sono } \\
\text { mudaram drasticamente, e que nos dias atuais, } \\
\text { com as novas tecnologias, as horas de sono } \\
\text { foram sacrificadas em favor de atividades } \\
\text { noturnas. A restrição crônica de sono pode } \\
\text { trazer efeitos no humor, cognição e outros } \\
\text { riscos que podem prejudicar o bem estar da } \\
\text { população. }\end{array}$ \\
\hline $\begin{array}{l}\text { Ocular hazards of blue-light } \\
\text { therapy in dermatology }\end{array}$ & $\begin{array}{l}\text { Daniel P. Walker, Heidi } \\
\text { R. Vollmer-Snarr, } \\
\text { Cheryl Lee D. Eberting }\end{array}$ & $2010^{25}$ & $\begin{array}{l}\text { O artigo apontou que a luz azul pode trazer } \\
\text { diversos efeitos negativos à retina, uma vez que } \\
\text { há receptores sensíveis a esta faixa de luz. } \\
\text { Ao fim, os autores indicam alguns meios de } \\
\text { proteger os olhos dos efeitos negativos da luz } \\
\text { azul, como a utilização de protetores oculares. }\end{array}$ \\
\hline $\begin{array}{l}\text { Population-level study links } \\
\text { short-wavelength } \\
\text { nighttime illumination with } \\
\text { breast cancer } \\
\text { incidence in a major } \\
\text { metropolitan area }\end{array}$ & $\begin{array}{l}\text { Nataliya Rybnikova, } \\
\text { Boris A. Portnov }\end{array}$ & $2018^{26}$ & $\begin{array}{l}\text { O estudo cruzou dados de satélite que } \\
\text { demonstravam a incidência de iluminação } \\
\text { noturna e dados da incidência de câncer de } \\
\text { mama em certa região. A luz artificial é capaz } \\
\text { de suprimir a melatonina noturna, alterando } \\
\text { vias e elevando o risco de câncer hormônio- } \\
\text { dependentes. }\end{array}$ \\
\hline $\begin{array}{l}\text { Efeitos da privação do sono na } \\
\text { ingestão alimentar }\end{array}$ & Sara Santos Teixeira & $2017^{27}$ & $\begin{array}{l}\text { Além da luz, o ciclo circadiano também é } \\
\text { sincronizado pela alimentação. Sendo assim, a } \\
\text { autora demonstra que a privação do sono leva a } \\
\text { desordens metabólicas que alteram também a } \\
\text { ingestão alimentar. }\end{array}$ \\
\hline $\begin{array}{l}\text { Protecting the Melatonin } \\
\text { Rhythm through Circadian } \\
\text { Healthy Light Exposure }\end{array}$ & $\begin{array}{l}\text { Maria Angeles Bonmati- } \\
\text { Carrion, Raquel } \\
\text { Arguelles-Prieto, Maria } \\
\text { Jose Martinez-Madrid, } \\
\text { Russel Reiter, Ruediger } \\
\text { Hardeland, Maria } \\
\text { Angeles Rol, Juan } \\
\text { Antonio Madrid }\end{array}$ & $2014^{28}$ & $\begin{array}{l}\text { Esta revisão aborda conhecimentos } \\
\text { aprofundados sobre a fisiologia do sistema } \\
\text { circadiano, demonstrando todo o sistema de } \\
\text { genes, proteínas e células que compõem a } \\
\text { ritmicidade biológica. Os autores abordam ainda } \\
\text { algumas maneiras que poderiam ser utilizadas } \\
\text { para proteger o ritmo, como a mudança no } \\
\text { comprimento de onda das luzes utilizadas no dia } \\
\text { a dia. }\end{array}$ \\
\hline $\begin{array}{l}\text { Qualidade de Sono de } \\
\text { Adolescentes em Contexto } \\
\text { Escolar }\end{array}$ & $\begin{array}{l}\text { Joana Andreia Costa } \\
\text { Pinto Marques }\end{array}$ & $2017^{29}$ & $\begin{array}{l}\text { Sendo a adolescência um período de mudanças } \\
\text { biológicas e sociais, a autora buscou relacionar } \\
\text { a má qualidade de sono neste período a fatores } \\
\text { associados, abordando aspectos fisiológicos e } \\
\text { comportamentais que podem levar os indivíduos } \\
\text { a uma má higiene do sono. }\end{array}$ \\
\hline
\end{tabular}


Tabela 2 (cont.). Apresentação dos resultados obtidos após estudo dos materiais.

\begin{tabular}{|c|c|c|c|}
\hline $\begin{array}{l}\text { Relação entre exposição à luz } \\
\text { em sala de aula, ciclo sono- } \\
\text { vigília e atenção em } \\
\text { adolescentes de diferentes } \\
\text { cidades do RN }\end{array}$ & Sabinne Danielle Galina & $2017^{30}$ & $\begin{array}{l}\text { O artigo trabalha a hipótese de que a } \\
\text { iluminação em sala de aula pode influenciar a } \\
\text { atenção em adolescentes ao interferir na } \\
\text { regulação do ciclo sono-vigília, que nos } \\
\text { adolescentes funciona de forma ligeiramente } \\
\text { diferente por se tratar de uma fase de } \\
\text { alterações corporais. A autora do estudo } \\
\text { realizou a pesquisa com adolescentes em fase } \\
\text { escolar a fim de confirmar a hipótese. }\end{array}$ \\
\hline $\begin{array}{l}\text { Relação entre uso do telefone } \\
\text { celular antes de dormir, } \\
\text { qualidade do sono e sonolência } \\
\text { diurna }\end{array}$ & $\begin{array}{l}\text { Carine Cristina Moraes } \\
\text { de Freitas, Agda Lopes } \\
\text { Donnabella Marconi } \\
\text { Gozzoli, } \\
\text { Juliana Naomi Konno, } \\
\text { Vera Lucia Ribeiro Fuess }\end{array}$ & $2017^{4}$ & $\begin{array}{l}\text { Os autores relacionaram a desregulação } \\
\text { circadiana com a utilização de aparelhos } \\
\text { celulares, o que poderia levar a uma má } \\
\text { qualidade de sono. Para testar a hipótese, } \\
\text { fizeram o teste em que indivíduos se abstiveram } \\
\text { do celular antes de dormir por } 15 \text { dias, } \\
\text { concluindo que a abstinência próxima ao } \\
\text { período de sono gerou uma melhora na } \\
\text { qualidade do sono e diminuição da sonolência } \\
\text { diurna. }\end{array}$ \\
\hline $\begin{array}{l}\text { The effect of nocturnal blue } \\
\text { light exposure from light- } \\
\text { emitting diodes on wakefulness } \\
\text { and energy metabolism the } \\
\text { following morning }\end{array}$ & $\begin{array}{l}\text { Momoko Kayaba, Kaito } \\
\text { Iwayama, } \\
\text { Hitomi Ogata, Yumi } \\
\text { Seya, Ken Kiyono, } \\
\text { Makoto Satoh, Kumpei } \\
\text { Tokuyama }\end{array}$ & $2014^{31}$ & $\begin{array}{l}\text { O experimento realizado pelos autores buscou } \\
\text { avaliar se a exposição à luz LED azul durante a } \\
\text { tarde, no período próximo ao de sono, teria } \\
\text { influência no sono e na vigília na manhã } \\
\text { seguinte. Para realizá-lo, os autores exporam } \\
\text { grupos de indivíduos à luz, ou à falta dela, em } \\
\text { ambiente controlado enquanto monitoravam os } \\
\text { indivíduos. }\end{array}$ \\
\hline $\begin{array}{l}\text { The Effects of the Removal of } \\
\text { Electronic Devices for } 48 \text { Hours } \\
\text { on Sleep in Elite } \\
\text { Judo Athletes }\end{array}$ & $\begin{array}{l}\text { Ian C. Dunican, David } \\
\text { T. Martin, Shona L. } \\
\text { Halson, Reid J. Reale, } \\
\text { Brian T. Dawson, } \\
\text { John A. Caldwell, } \\
\text { Maddison J. Jones, } \\
\text { Peter R. Eastwood }\end{array}$ & $2017^{32}$ & $\begin{array}{l}\text { Distúrbios de sono podem afetar negativamente } \\
\text { o desempenho de atletas e recente uso de } \\
\text { dispositivos luminosos pode estar contribuindo } \\
\text { para tal. Pensando nisso, este trabalho testou } \\
\text { se a remoção de dispositivos eletrônicos } \\
\text { durante o período próximo ao sono por dois dias } \\
\text { consecutivos geraria mudanças perceptíveis no } \\
\text { sono dos indivíduos testados. Ao fim, } \\
\text { concluíram que o tempo do estudo não gerou } \\
\text { mudanças significativas, uma vez que o mesmo } \\
\text { se deu em um curto período de tempo. }\end{array}$ \\
\hline $\begin{array}{l}\text { Timing of light exposure affects } \\
\text { mood and brain circuits }\end{array}$ & TA Bedrosian, RJ Nelson & $2016^{33}$ & $\begin{array}{l}\text { Esta revisão explora a ideia de que a luz } \\
\text { artificial à noite causa impactos no sistema } \\
\text { circadiano. Além de mostrar o funcionamento } \\
\text { deste sistema, os autores demonstraram os } \\
\text { impactos causados por sua desregulação, dando } \\
\text { enfoque no humor. Nas conclusões dão } \\
\text { sugestões de estratégias que podem minimizar } \\
\text { essa exposição noturna, como ajuste de } \\
\text { comprimento de onda nas lâmpadas LED e uso } \\
\text { de lentes bloqueadoras de luz azul. }\end{array}$ \\
\hline $\begin{array}{l}\text { Uso de dispositivos eletrônicos } \\
\text { e padrões do ciclo vigília/sono } \\
\text { De crianças e adolescentes } \\
\text { urbanos }\end{array}$ & Tâmile Stella Anacleto & $2017^{34}$ & $\begin{array}{l}\text { A autora relacionou o uso de dispositivos } \\
\text { eletrônicos com distúrbios no sistema circadiano } \\
\text { e, através de uma amostra de alunos, realizou } \\
\text { este estudo. Sua hipótese foi confirmada ao } \\
\text { concluir que sujeitos que utilizam de algum } \\
\text { dispositivo eletrônico antes de dormir têm uma } \\
\text { pior qualidade de sono. }\end{array}$ \\
\hline $\begin{array}{l}\text { Os problemas causados pelo } \\
\text { uso excessivo de smartphones }\end{array}$ & $\begin{array}{l}\text { Adriellen Fernandes de } \\
\text { Souza, Ana Clara de } \\
\text { Oliveira Miranda }\end{array}$ & $2018^{35}$ & $\begin{array}{l}\text { Nesta revisão as autoras relacionaram a } \\
\text { utilização de smartphones com diversos riscos } \\
\text { aos usuários, nos casos de uso incorreto do } \\
\text { aparelho. Alguns dos riscos citados foram à } \\
\text { visão, audição e ao sono. }\end{array}$ \\
\hline
\end{tabular}


Sendo tão importante para nosso sistema visual, ressalta-se que a composição da luz visível nada mais é que uma pequena parte do sistema de ondas eletromagnéticas, geradas a partir da oscilação de elétrons livres e capazes de se propagar no vácuo. Tais elétrons oscilam em forma de onda e o que define onde determinada onda se encontra no espectro são dois aspectos: comprimento da onda, que é a distância percorrida pelo elétron em sua oscilação, e a frequência, que é o tempo que o elétron leva para percorrer essa distância.

Portanto, percebe-se que quanto menor o espaço a ser percorrido pelo elétron, menor o tempo para o elétron completar a oscilação².

Tendo em vista que o espectro eletromagnético é dividido e organizado por comprimento de onda e frequência, a luz visível se encontra numa estreita faixa (medindo de 380 a $740 \mathrm{~nm}$ ) entre o Infravermelho e o Ultravioleta, sendo subdividida em cores. Newton realizou experimentos com a luz e conseguiu separá-la em sete cores: vermelho, laranja, amarelo, verde, ciano, azul e violeta. Nosso olho, porém, capta somente vermelho, verde e azul e nossa percepção das outras cores se dá a partir da mistura dessas três².

Atualmente, a luz é utilizada cotidianamente através dos dispositivos eletrônicos, mas não é nova a necessidade humana de realizar cálculos, processar e armazenar dados. A história remonta o surgimento das primeiras ferramentas 
de cálculos, como o ábaco, há milênios antes de Cristo. Mas somente por volta dos anos 1930 e 1940 que começaram a surgir os primeiros computadores propriamente ditos. Nos primórdios da computação, as máquinas eram eletromecânicas e sua intenção era a de realizar cálculos automaticamente ${ }^{1}$.

Entretanto, em 1946 foi lançado o Electronic Numerical Integrator and Computer (E.N.I.A.C.), que ficou conhecido como o primeiro computador eletrônico criado. A partir de então, muitos avanços foram feitos, como a invenção do Transistor em 1948, que permitiu a fabricação de pequenos chips com grande capacidade de processamento ${ }^{1}$.

Por consequência de sua popularização, o crescimento no número de pessoas proprietárias de dispositivos eletrônicos é nítido. Segundo dados do Instituto Brasileiro de Geografia e Estatística (IBGE) em sua pesquisa anual, a Pesquisa Nacional por Amostra de Domicílios (PNAD), em 58,9\% dos domicílios pesquisados em 2001 havia acesso a telefonia e apenas em 7,8\% havia acesso à telefonia móvel. No mesmo ano, $12,6 \%$ das residências pesquisadas tinham microcomputadores, e apenas $8,6 \%$ do total contava com acesso à internet ${ }^{37}$. Num período de 10 anos, em 2011, o telefone já estava em $89,9 \%$ dos domicílios pesquisados e $49,7 \%$ contava somente com telefonia móvel. Quanto à presença de microcomputadores, no mesmo período, $42,9 \%$ relataram ter o aparelho e $36,5 \%$ dos pesquisados relataram ter acesso à internet ${ }^{38}$. Os dados supracitados 
foram condensados em um gráfico para uma melhor visualização do conteúdo e este pode ser encontrado na Figura 1.

Figura 1. Presença de telefones, celulares, microcomputadores e acesso à internet nos domicílios brasileiros em 2001, em comparação ao ano de 2011.

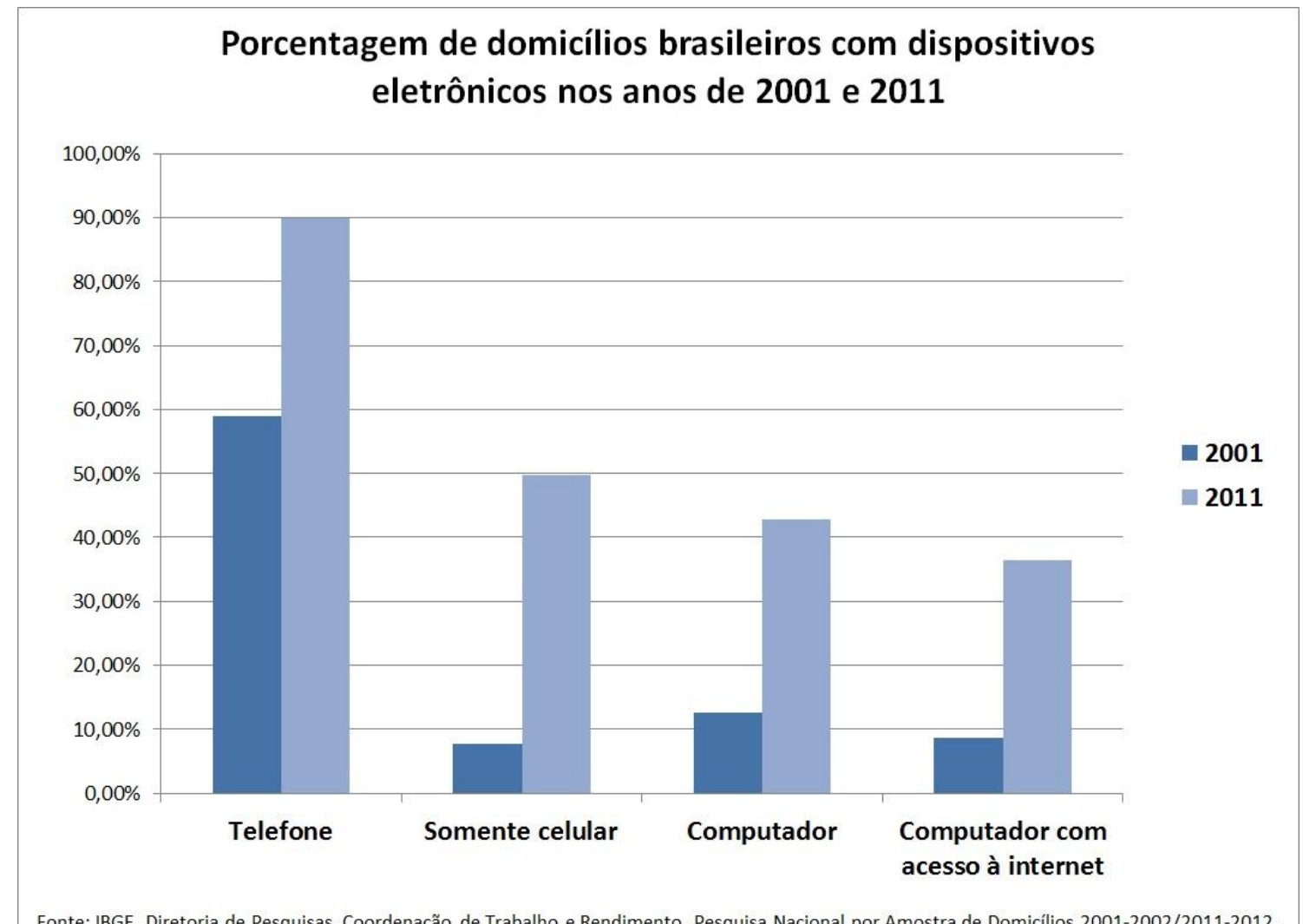

Embora as novas tecnologias tenham se popularizado rapidamente devido à sua utilidade, é possível que estes aparelhos não tragam apenas benefícios, mas também riscos aos usuários. O excesso da utilização de dispositivos emissores de luz pode desencadear diversos problemas a 
diferentes estruturas e mecanismos, como por exemplo, à visão, audição e ao sono ${ }^{35}$.

\section{O ciclo circadiano e os riscos da sua desregulação}

O ser humano apresenta uma alternância cíclica de atividade e repouso, esta alternância é denominada de ciclo circadiano, tendo uma variação de aproximadamente $24 \mathrm{~h}$ e sendo determinado por fatores biológicos dos quais a resposta à variação de luz é o mais evidente, e fatores sociais como horários de trabalho e lazer $^{5}$.

Como citado, a luz permite ao cérebro uma interpretação das informações captadas pelos olhos, isso se dá através de células especializadas na transmissão de estímulos luminosos. Dentre os tipos de células fotossensíveis encontradas nos olhos, podemos citar os cones e os bastonetes, responsáveis pela recepção de estímulos visuais, e as células ganglionares intrinsecamente fotossensíveis (ipRGCs), localizadas na retina e responsáveis pela captação de estímulos luminosos não visuais, contendo um fotopigmento chamado melanopsina 20 .

As ipRGCs enviam sinais para o núcleo supraquiasmático (NSQ), localizado no hipotálamo anterior, sendo este responsável pela geração do relógio biológico interno. Este complexo sistema de realimentação se dá através de um mecanismo de transcrição dos genes conhecidos como Genes Circadianos, ou Genes do Relógio, os responsáveis pela oscilação do relógio biológico. A partir 
disso, o NSQ controla a secreção da Melatonina, um importante hormônio do ciclo circadiano ${ }^{11}$.

A melatonina ( $\mathrm{N}$-acetil-5-metoxi-triptamina) é sintetizada na glândula pineal, um pequeno órgão do sistema endócrino localizado no cérebro, sendo secretada no período noturno, horário no qual o corpo se encontra em ausência de luz.

Em virtude de sua ação no ritmo circadiano, essa substância ficou conhecida com hormônio do sono, mas além da atuação cronobiológica, sua atividade no corpo inclui ação anti-inflamatória, imunológica e antitumoral ${ }^{22}$.

Resumidamente, o ciclo fisiológico do sono funciona da seguinte forma: os olhos captam a luz ambiente e esta serve como indicativo para o corpo se ele está num período noturno ou diurno. A partir disso o corpo se regula de maneira que o sono ocorra no horário de escuridão e a vigília ocorra no período em que há presença de luz. Vale ressaltar que este reconhecimento de luz pelas células retinianas é mais sensível às faixas do espectro correspondentes à luz azul, devido à abundância da mesma de $\operatorname{dia}^{16,26}$.

Conforme mencionado, a utilização de dispositivos emissores de luz pode vir a ser um risco aos usuários, isso acontece devido à desregulação circadiana que ocorre pela utilização deles no período noturno. A luz artificial à noite (ou ALAN, da sigla em inglês) é prejudicial, pois desencadeia a sinalização luminosa ao NSQ e consequentemente a supressão da secreção de Melatonina. 
Assim sendo, o corpo sofre com atrasos nas fases de sono e vigília do ciclo circadiano, agindo como se estivesse em um ambiente diurno, mantendo a vigília nos momentos em que deveria estar na fase de sono ${ }^{8}$.

Ademais, estudos recentes indicaram uma possível relação entre a ALAN e impactos na saúde, como a incidência de câncer. Algumas vertentes tentam explicar essa ligação, uma delas explica que a desregulação no ritmo diário do corpo causa uma baixa no sistema imune e aumentando a susceptibilidade ao câncer e outras doenças. Outra hipótese explica que, nas mulheres, a supressão de melatonina culminaria na alteração da afinidade de receptores de estrogênio, ocasionando assim um aumento na vulnerabilidade a cânceres relacionados a fatores hormonais, como o câncer de mama26.

\section{CONCLUSÃO}

Haja vista a importância do Ciclo Circadiano para o corpo e a manutenção da homeostasia, ressalta-se que a população precisa ser alertada para um uso moderado dos dispositivos emissores de luz. Além de reeducação, artifícios para diminuir a desregulação dos relógios internos do corpo podem ser benéficos.

Assim sendo, a utilização de lentes oculares com filtros de luz, aplicativos para diminuir a emissão de luz nociva pelas telas, uso restrito nos períodos noturnos, entre outros artifícios podem ser utilizados para que o corpo reaja 
corretamente às mudanças de luz e que o indivíduo tenha uma melhora na qualidade de vida.

\section{REFERÊNCIAS}

1.Filho CF. História da Computação: O Caminho do Pensamento e da Tecnologia. Porto Alegre: EDIPUCTS, 2007, 205 p. https://books.google.com.br/books?id= YRy1|KnniEC\&hl=pt-BR

2. Rocha JC. Cor luz, cor pigmento e os sistemas RGB e CMY. Rev Belas Artes 2010;2:1-19.

http://www.belasartes.br/revistabelasartes/downloads/artigos/3/corluz-cor-pigmento-e-os-sistemas-rgb-e-cmy.pdf

3.Seito TH. Ciclos de atividade/repouso e alimentação/jejum associados ao uso de equipamentos eletrônicos: aspectos comportamentais e padrões temporais (Tese). São Paulo: Universidade de São Paulo; 2017.

https://www.teses.usp.br/teses/disponiveis/47/47135/tde-21032017111443/pt-br.php

4.Freitas CCM, Gozzoli ALDM, Konno JN, Fuess VLR. Relação entre uso do telefone celular antes de dormir, qualidade do sono e sonolência diurna. Rev Med 2017;96:14-20. https://doi.org/10.11606/issn.1679-9836.v96i1p14-20

5.Cercatti MJP. A Frequência da Utilização de Videojogos e sua Influência na Qualidade do Sono de Crianças em Idade Escolar. Lisboa: Universidade Autônoma de Lisboa, 2018.

http://hdl.handle.net/11144/3899

6.Lima RC. A luz irrompe onde já nenhum sol brilha. Lisboa: Centro de Literaturas e Culturas Lusófonas e Europeias. 2018, 24 p. https://recipp.ipp.pt/handle/10400.22/12883

7.Diogo FMC. Análise comparativa dos padrões de sono entre adolescentes do ensino médio e superior (monografia). Natal: Universidade Federal do Rio Grande do Norte, 2018, 76p. https://monografias.ufrn.br/jspui/handle/123456789/7898

8. Haim A, Zubidat AE. Artificial light at night: Melatonin as a mediator between the environment and epigenome. Philos Trans R Soc Lond $B$ Biol Sci 2015;370:20140121.

http://dx.doi.org/10.1098/rstb.2014.0121

9.Zubidat $A E$, Haim A. Artificial light-At-night-a novel lifestyle risk factor for metabolic disorder and cancer morbidity. J Basic Clin Physiol Pharmacol 2017;28:295-313.

http://dx.doi.org/10.1515/jbcpp-2016-0116

10. Harb ABC. Aspectos cronobiologicos da síndrome do comer noturno (Tese). Porto Alegre: Universidade Federal do Rio Grande do Sul; 2013. https://lume.ufrgs.br/handle/10183/87175

11. Touitou Y, Reinberg A, Touitou D. Association between light at night, melatonin secretion, sleep deprivation, and the internal clock: 
Health impacts and mechanisms of circadian disruption. Life Sci 2017;173:94-106. http://dx.doi.org/10.1016/j.Ifs.2017.02.008

12.Garcia ADS. Avaliação da qualidade do sono na perspectiva do conforto para o pós-graduando em enfermagem (dissertação). Rio de Janeiro: Universidade Federal do Estado do Rio de Janeiro - UNIRIO; 2018. http://www.unirio.br/ppgenf/dissertacoes/dissertacoes-ppgenfunirio-ano-2018/dissertacao-andrea-dos-santos

13.Leonardo MEM. Avaliação do efeito do jogo "quarto perfeito: aprenda a dormir bem" nos parâmetros e hábitos de sono de crianças saudáveis (Tese). Natal: Universidade Federal do Rio Grande do Norte; 2018, 191p.

https://repositorio.ufrn.br/jspui/handle/123456789/25654

14.Sander B, Markvart J, Kessel L, Argyraki A, Johnsen K. Can sleep quality and wellbeing be improved by changing the indoor lighting in the homes of healthy, elderly citizens? Chronobiol Int 2015;32:104960. http://dx.doi.org/10.3109/07420528.2015.1056304

15.Silva LC, Maia LD, Pinheiro DR, Matias LSM, Salvo VF, André JO, et al. Correlação entre a Exposição Diária à Luz Azul Violeta Emitida por Dispositivos Digitais e a Visão de Adultos Jovens. Saúde em Rev 2015;15:47-55. https://doi.org/10.15600/2238-1244/sr.v15n41p4765

16.Thorne HC, Jones KH, Peters SP, Archer SN, Dijk DJ. Daily and seasonal variation in the spectral composition of light exposure in humans. Chronobiol Int 2009;26:854-66.

http://dx.doi.org/10.1080/07420520903044315

17.Rabstein S, Burek K, Lehnert M, Beine A, Vetter C, Harth V, et al. Differences in twenty-four-hour profiles of blue-light exposure between day and night shifts in female medical staff. Sci Total Environ 2019;653:1025-33.

http://dx.doi.org/10.1016/j.scitotenv.2018.10.293

18. Lee S, Kakitsuba N, Katsuura T. Do green-blocking glasses enhance the nonvisual effects of white polychromatic light? J Physiol Anthropol 2018;37:29. http://dx.doi.org/10.1186/s40101-018-01893

19.Giménez MC, Beersma DGM, Bollen P, Van Der Linden ML, Gordijn MCM. Effects of a chronic reduction of short-wavelength light input on melatonin and sleep patterns in humans: Evidence for adaptation. Chronobiol Int 2014;31:690-7.

http://dx.doi.org/10.3109/07420528.2014.893242

20.Tosini G, Ferguson I, Tsubota K. Effects of blue light on the circadian system and eye physiology. Mol Vis 2016;22:61-72.

https://www.ncbi.nlm.nih.gov/pmc/articles/PMC4734149/pdf/mvv22-61.pdf

21.Cunha JP, Ferreira J, Paiva T, Castanheira-dinis A. Filtro Amarelo e o Ritmo Circadiário. Oftalmologia 2011;35:53-60.

https://www.spoftalmologia.pt/wpcontent/uploads/2011/01/revista spo n1 2011_pp.53-60.pdf

22. Kasecker FG, Nunes CP. Melatonina e glândula pineal. Rev Fac Med Teresóp 2017;1:109-29. 
http://www.revista.unifeso.edu.br/index.php/faculdadedemedicinadet eresopolis/article/view/590/389

23.Smolensky MH, Sackett-Lundeen LL, Portaluppi F. Nocturnal light pollution and underexposure to daytime sunlight: Complementary mechanisms of circadian disruption and related diseases. Chronobiol Int $2015 ; 32: 1029-48$.

http://dx.doi.org/10.3109/07420528.2015.1072002

24.Silveira FAS. O impacto da restrição crónica de sono na função cognitiva e humor em adolescentes (Tese). Lisboa: Universidade de Lisboa; 2017.

https://repositorio.ul.pt/bitstream/10451/31302/1/FernandaASSilveir a.pdf

25.Walker DP, Vollmer-Snarr HR, Eberting CLD. Ocular hazards of blue-light therapy in dermatology. J Am Acad Dermatol 2012;66:1305. http://dx.doi.org/10.1016/j.jaad.2010.11.040

26. Rybnikova N, Portnov BA. Population-level study links shortwavelength nighttime illumination with breast cancer incidence in a major metropolitan area. Chronobiol Int 2018;1-11. https://doi.org/10.1080/07420528.2018.1466802

27.Teixeira SS. Efeitos da privação do sono na ingestão alimentar (Tese). Porto: Universidade do Porto; 2017. https://repositorioaberto.up.pt/bitstream/10216/106002/2/202787.pdf

28.Bonmati-Carrion MA, Arguelles-Prieto $R$, Martinez-Madrid MJ, Reiter R, Hardeland R, Rol MA, et al. Protecting the melatonin rhythm through circadian healthy light exposure. Int $\mathrm{J}$ Mol Sci 2014;15:23448-500. https://doi.org/10.3390/ijms151223448

29. Marques JACP. Qualidade de Sono de Adolescentes em Contexto Escola (Tese). Coimbra: Escola Superior de Enfermagem de Coimbra; 2017.https://repositorio.esenfc.pt/private/index.php?process=downlo ad\&id $=52968 \&$ code $=249$

30.Galina SD. Relação entre exposição à luz em sala de aula, ciclo sono-vigília e atenção em adolescentes de diferentes cidades do RN (Tese). Natal: Universidade Federal do Rio Grande do Norte; 2017. https://repositorio.ufrn.br/jspui/handle/123456789/23843

31. Kayaba M, Iwayama K, Ogata $\mathrm{H}$, Seya $\mathrm{Y}$, Kiyono K, Satoh M, et al. The effect of nocturnal blue light exposure from light-emitting diodes on wakefulness and energy metabolism the following morning. Environ Health Prev Med 2014;19:354-

61. https://doi.org/10.1007/s12199-014-0402-x

32. Dunican IC, Martin DT, Halson SL, Reale RJ, Dawson BT, Caldwell JA, et al. The effects of the removal of electronic devices for 48 hours on sleep in elite judo athletes. J Strength Cond Res 2017;31:28329. https://doi.org/10.1519/JSC.0000000000001697

33.Bedrosian TA, Nelson RJ. Timing of light exposure affects mood and brain circuits. Transl Psychiatry 2017;7:1-9.

http://dx.doi.org/10.1038/tp.2016.262

34. Anacleto TS. Uso de dispositivos eletrônicos e padrões do ciclo vigília/sono de crianças e adolescentes urbanos (Tese). Cutitiba: Universidade Federal do Paraná; 2017. 
https://acervodigital.ufpr.br/handle/1884/47360

35.Souza AF, Miranda ACO. Os problemas causados pelo uso excessivo de smartphones (Monografia). Caucaia: Instituto Federal do Ceará-Campus Caucaia; 2018. http://prpi.ifce.edu.br/nl/ lib/file/doc4147-Trabalho/ARTIGO terminado.pdf

36.Guyton AC. Fisiologia Humana. 6th ed. Rio de Janeiro: Guanabara Koogan; 1998. 555p.

37.Instituto Brasileiro de Geografia e Estatistica. Pesquisa Nacional por Amostra de Domicilios: síntese de indicadores 2001/IBGE, Departamento de Emprego e Rendimento. Rio de Janeiro: IBGE; 2002. https://biblioteca.ibge.gov.br/index.php/bibliotecacatalogo?view $=$ detalhes\&id $=21061$

38.Instituto Brasileiro de Geografia e Estatistica. Pesquisa Nacional por Amostra de Domicilios: síntese de indicadores 2011. Rio de Janeiro: IBGE; 2012; 281p.

https://biblioteca.ibge.gov.br/index.php/biblioteca-

catalogo?view $=$ detalhes\&id $=261566$ 